\title{
Effects of low and high deprenyl dose on antioxidant enzyme activities in the adult rat brain
}

\author{
Maria Lalkovicova ${ }^{1}$, Frantiska Horvathova ${ }^{2}$, Igor Sulla ${ }^{3}$, Jozef Mihalik ${ }^{2}$ and Viera Danielisova ${ }^{1}$ \\ ${ }^{1}$ Institute of Neurobiology, Slovak Academy of Sciences, Kosice, Slovakia \\ ${ }^{2}$ Department of Anatomy, Medical Faculty, Safarik University, Kosice, Slovakia \\ ${ }^{3}$ Department of Anatomy, Histology and Physiology, University of Veterinary Medicine and Pharmacy, Kosice, Slovakia
}

\begin{abstract}
We evaluated the effects of low dose deprenyl (LDD, $0.0025 \mathrm{mg} / \mathrm{kg}$ per day) and high dose deprenyl (HDD, $0.25 \mathrm{mg} / \mathrm{kg}$ per day) treatment of male Wistar rats for 30 days on the activities of SOD and CAT in the cortex, striatum, and hippocampus. Total SOD and MnSOD activities were increased with $\operatorname{LDD}(p<0.05)$ in the cortex $(0.74 \pm 0.03 ; 0.31 \pm 0.02)$, striatum $(0.75 \pm 0.02$; $0.27 \pm 0.03)$ and CA1 region of the hippocampus $(0.75 \pm 0.02 ; 0.29 \pm 0.03)$ compared to the control $(0.53 \pm 0.02 ; 0.15 \pm 0.02)$, but reduced $(p<0.05)$ with HDD compared to the LDD group. CAT activity was increased $(p<0.05)$ with LDD in the cortex $(27.34 \pm 3.11)$, striatum $(22.22 \pm 1.85)$, and hippocampal CA1 region $(16.62 \pm 2.15)$ compared to control $(10.33 \pm 1.01)$, while a decrease was induced by HDD in the striatum $(9.85 \pm 1.09)$ compared to LDD. There was a significant $(p<0.05)$ difference in number of Fluoro Jade B positive CA1 neurons induced by LDD $(21.14 \pm 2.85 \%)$ and $\operatorname{HDD}(12.61 \pm 1.42 \%)$, as well as the number of NeuN positive CA1 neurons after LDD $(183.35 \pm 11.14$ cells $/ \mathrm{mm})$ and HDD $(238.45 \pm 14.11$ cells $/ \mathrm{mm}(p<0.05)$. Deprenyl showed a potential in improving the neurological outcome and reducing the oxidative damage.
\end{abstract}

Key words: Deprenyl — Endogenous antioxidant enzymes - Hippocampus

Abbreviations: CAT, catalase; CuZnSOD, copper-zinc superoxide dismutase; DAB, diaminobenzidine; GPx, gluthatione peroxidase; HDD, high dose deprenyl; LDD, low dose deprenyl; MAO, monoamine oxidase; MnSOD, manganese superoxide dismutase; PBS, phosphate-buffered saline; SOD, superoxide dismutase.

\section{Introduction}

Deprenyl (N-methyl-N-(1-methyl-2-phenyl-ethyl)-prop2-en-1-amine, $\mathrm{C}_{13} \mathrm{H}_{19} \mathrm{~N}$, CID: 5288103 ) is a selective inhibitor of monoamine oxidase (MAO) type $\mathrm{B}$ which is responsible for the oxidation of dopamine in the brain. MAO is an enzyme responsible for the degradation of aminergic neurotransmitters; dopamine, noradrenaline and serotonin and dietary amines; MAO inhibitors are classical antidepressant drugs (Tazik et al. 2009). Furthermore, by inducing antioxidant enzymes and decreasing the formation of reactive oxygen species, deprenyl is able to combat oxida-

Correspondence to: Maria Lalkovicova, Institute of Neurobiology, Slovak Academy of Sciences, Soltesovej 4, 04001 Kosice, Slovakia E-mail: lalkovicova@saske.sk tive challenges implicated as a common causative factor in neurodegenerative diseases.

Superoxide dismutases (SOD) are a family of intracellular enzymes that catalyse dismutation and protect against oxygen free radicals by increasing the removal of superoxide radicals $\left(\mathrm{O}_{2}^{-}\right)$, which damage the membrane and biological structures. Intracellular izoenzymes CuZnSOD (SOD1) and MnSOD (SOD2, different metal-coordinated forms of SOD) are present in the cytosole and mitochondrial matrix, in astrocytes and neurons. Catalase (CAT) has been shown to be responsible for the detoxification of significant amounts of hydrogen peroxide (Subramanian and James 2010). SOD activity can be increased after treatment with deprenyl because of the anti-radical effects of deprenyl and its antioxidant role (Maruyama and Naoi 1999; Thomas 2000; Kitani et al. 2002; Saravanan et al. 2006). A decrease in the activity of SOD 
can be due to a decrease in the ability of the mitochondrial protective mechanism against the disorganising effects of free radicals. This reaction could also contribute to the decline in SOD activity during aging, leading to overloading of oxygen radicals. All of the mentioned results are in accordance with an earlier study by Zhang et al. (2003), which indicated that SOD and glutathione peroxidase (GPx) activities decrease slightly with age. Deprenyl is known to upregulate the activities of antioxidant enzymes in the rat brain (Kitani et al. 1996). However, there are no direct data on the effect of deprenyl on antioxidant enzyme activities in the ischemic rat brain. Therefore in the present work we intended to study the effect of deprenyl treatment on the endogenous enzymes activity in brain and by that to contribute to the knowledge about possible neuroprotective effects of deprenyl in the hippocampus, striatum and cortex, which could preserve memory and cognitive abilities in the case of ischemia. Deprenyl is used for the treatment of Parkinson's disease because its effects can attenuate the progressive degeneration of nigro-striatal dopaminergic neurons during aging and neurodegenerative disorders (Foley et al. 2000; Maruyama et al. 2000). Since the brain changes during aging process, age-related neurodegenerative diseases occur as a result of neurodegeneration. The destruction of the neurons in the aged brain caused by oxidative stress in the aged brain are evidenced, as well as increased vulnerability to oxidative stress seen in the aging population (Rego and Oliveira 2003). Increase of the oxidative stress during aging leads to widespread damage to cellular components, and manifesting in declines in motor and cognitive abilities. Deprenyl is thought to protect against age-related cognitive deficits by improving long-term learning memory in the aging brain (Bickford et al. 1997; Kiray et al. 2006; Singh et al. 2012).

In this study, we aimed to examine the effects of deprenyl treatment with a low dose (LDD, $0.0025 \mathrm{mg} / \mathrm{kg}$ per day, Sigma) and a high dose of deprenyl (HDD, $0.25 \mathrm{mg} / \mathrm{kg}$ per day) on SOD and CAT enzyme activities in the cortex, striatum and two hippocampal regions of rats. We also observed damaged (with Fluoro Jade B Staining) and surviving (with immunostaining for a neuronal marker NeuN) neurons in the CA1 region of the hippocampus after the administration of deprenyl. We wanted to examine application of different dosage of deprenyl administration in comparison with already used regimes and its influence on the enzymatic activity in the brain tissue of male rats. Our focus lays on the prevention of damage caused by the processes of oxidative stress which play an important role in various neurological and psychiatrical diseases.

\section{Materials and Methods}

Adult male albino Wistar rats ( $n=6$ at each time point) weighing $390 \pm 50 \mathrm{~g}$, aged 8-9 weeks, were maintained on a $12 \mathrm{~h}$ light/dark cycle and given food and water ad libitum. Albino Wistar rats are most applicable strain for neurological experiments since they covers all the requirements necessary for comparison with humans. The experiments were carried out in accordance with the protocol for animal care approved by both the Slovak Health Committee (1998) and the European Communities Council Directive (86/609/ EEC). The rats were randomly divided into three groups and were injected intraperitoneally daily for 30 days with either saline (control animals), with a low dose of deprenyl (LDD, $0.0025 \mathrm{mg} / \mathrm{kg}$ per day, Sigma M003) or with a high dose of deprenyl (HDD, $0.25 \mathrm{mg} / \mathrm{kg}$ per day) dissolved in saline.

HDD is the therapeutic-used dosage for deprenyl, while LDD is $1 \%$ of the standard therapeutic dosage. We measured the activity of antioxidant enzymes in the brain tissue and further examined our results with histological and immunocytochemical analyses.

\section{Spectrophotometry analysis}

At the end of the experiment, rats were decapitated under halothane anaesthesia, and then brains were quickly removed and maintained at a cold temperature. Native brains were immediately cooled to $4^{\circ} \mathrm{C}$, divided into cortex, striatum and hippocampal CA1 and dentate gyrus enriched fractions, which were homogenised in an extraction medium containing $0.1 \mathrm{~mol} / 1$ sodium phosphate $(\mathrm{pH} 7.8)$ for SOD activity and $0.1 \mathrm{~mol} / \mathrm{l}$ sodium phosphate $(\mathrm{pH} 7.4)$ for CAT activity, then centrifuged for $10 \mathrm{~min}$ at $12000 \times g$ to separate the postmitochondrial supernatant. The supernatants were divided into $100 \mu \mathrm{l}$ aliquots and frozen at $-70^{\circ} \mathrm{C}$ for enzyme and protein assays.

SOD activity assay involved a slight modification of the indirect inhibition assay developed by Sun et al. (1988). Xanthine-xanthine oxidase was utilised to generate a superoxide flux. The absorbance obtained from nitroblue tetrazolium (NBT, p-nitrotetrazoliumblue grade III, Sigma) reduction to blue formazan by superoxide was determined at $560 \mathrm{~nm}$ spectrophotometrically at room temperature. The SOD in the sample competes for superoxide, inhibiting the reaction rate of superoxide with NBT. The rate of NBT reduction in the absence of tissue was used as the reference rate $(0.020 \pm 0.005$ absorbance $/ \mathrm{min})$. The standard assay substrate mixture contained in $2 \mathrm{ml}$ was: $1 \mathrm{~mol} / \mathrm{l}$ xanthine (Sigma), $0.1 \mathrm{~mol} / 1 \mathrm{EDTA}, 5.6 \times 10^{-2} \mathrm{~mol} / 1 \mathrm{NBT}$ and $1 \mathrm{mg} /$ $\mathrm{ml}$ BSA (bovine serum albumin, Fluka) in $0.1 \mathrm{~mol} / \mathrm{l}$ sodium phosphate ( $\mathrm{pH}$ 7.8). The data were plotted as percentages of inhibition versus protein concentration. One unit (U) of SOD activity was defined as the amount that reduced the absorbance change by $50 \%$, and results were normalised on the basis of total protein content (U/mg protein). $\mathrm{CuZnSOD}$ was differentiated from MnSOD by the addition of $2 \mathrm{mmol} / \mathrm{l}$ sodium cyanide to inhibit the activity of CuZnSOD. CuZn- 
SOD activity was calculated as the difference between total SOD and MnSOD activity as in a previous report (McIntosh et al. 1998).

CAT activity was determined using Goth's spectrophotometric method (Goth 1991) in which the supernatant was incubated with hydrogen peroxide as the substrate; the enzymatic reaction was stopped by the addition of $32 \mathrm{mmol} / \mathrm{l}$ ammonium molybdate. The intensity of the yellow complex formed by molybdate and hydrogen peroxide was measured at $405 \mathrm{~nm}$. The catalase activity is given in $\mathrm{U} / \mathrm{mg}$ protein. Total protein concentrations were determined using the method described by Bradford (1976) and analyticalgrade BSA was used to establish a standard curve.

\section{Histological confirmation}

The animals were killed by transcardiac perfusion performed under deep anaesthesia (chloral hydrate $400 \mathrm{mg} / \mathrm{kg}$, i.p. Sigma). Perfusion via the left ventricle started with a washout of blood vessels with $200 \mathrm{ml}$ of $0.9 \% \mathrm{NaCl}$. Brains were perfusion-fixed with $4 \%(\mathrm{w} / \mathrm{v})$ paraformaldehyde solution in phosphate buffer saline, removed and postfixed overnight in the same fixative prior to vibratome sectioning. Then, $33 \mu \mathrm{m}$ coronal sections of brain were prepared at the level of bregma $-3.3 \pm 0.2 \mathrm{~mm}$ for the hippocampus and randomly selected for Fluoro Jade B used to stain all degenerating neurons, regardless of the mechanism of cell death, and NeuN staining used to visualise neurons present in the CA1 region 30 days after administration of either saline or the low/high dose of deprenyl.

\section{Fluoro-Jade B staining}

Sections were mounted on $2 \%$ gelatin-coated slides and then dried on a slide warmer at $50^{\circ} \mathrm{C}$ for $30 \mathrm{~min}$. The slides were then immersed in a solution containing $1 \%$ sodium hydroxide in $80 \%$ alcohol for $5 \mathrm{~min}$. This was followed by $2 \mathrm{~min}$ in $70 \%$ alcohol and $2 \mathrm{~min}$ in distilled water. The slides were then transferred to a solution of $0.06 \%$ potassium permanganate for $10 \mathrm{~min}$, and subsequently rinsed in distilled water for $2 \mathrm{~min}$. After $20 \mathrm{~min}$ in the staining solution, containing 0.0004\% Fluoro Jade B dye (Histo-Chem Inc., USA), the slides were rinsed three times for $1 \mathrm{~min}$ in distilled water. Excess water was removed by briefly (about $15 \mathrm{~s}$ ) draining the slides vertically on a paper towel. The slides were then placed on a slide warmer set at approximately $50^{\circ} \mathrm{C}$ until they were fully dry (Schmued and Hopkins 2000). The dry slides were cleared by immersion in xylene for at least a minute before coverslipping with DPX Mountant for histology (FlukaChemie AG, Switzerland). The slides were examined using an Olympus BX 51 fluorescent microscope with a DP 50 digital camera. Positive cells were counted in the middle of the linear part of eight different CA1 fields from each animal and expressed as the average of positive pyramidal neurons per $1 \mathrm{~mm}$ of CA1 length. Neuronal cell count was performed by an investigator who was unaware of the treatment conditions, using Image Tool software (UTHSCSA, San Antonio, USA).

\section{Immunocytochemistry}

Immunocytochemistry was performed on the prepared coronal free-floating $33 \mu \mathrm{m}$ vibratome sections. Sections containing the hippocampus were immunostained for NeuN, a neuronal marker. Briefly, the sections were incubated overnight at $4^{\circ} \mathrm{C}$ with NeuN antibody (Chemicon International, Temecula, USA, 1:500) in $0.1 \mathrm{~mol} / 1 \mathrm{PBS}(\mathrm{pH}$ 7.4) with $0.2 \%$ Triton-X. After washing with $0.1 \mathrm{~mol} / \mathrm{l} \mathrm{PBS}$ ( $\mathrm{pH} 7.4$ ) with $0.2 \%$ Triton-X, the secondary anti-mouse IgG antibody was applied for $90 \mathrm{~min}$ at room temperature. After further washing, ABC Elite (Vector Laboratories, Burlingame, USA) was applied for $90 \mathrm{~min}$, then the slides were rinsed with PBS (phosphate-buffered saline) followed by Tris buffer ( $\mathrm{pH}$ 7.6), and reacted with $\mathrm{DAB}$ (diaminobenzidine) ( $0.1 \mathrm{~mol} / \mathrm{l}$ Tris, $0.04 \% \mathrm{DAB}, 0.033 \% \mathrm{H}_{2} \mathrm{O}_{2}$ ); the reaction was stopped with phosphate buffer. The slides were dehydrated, cleared, and coverslipped for analysis.

\section{Statistical analysis}

The results are presented as mean $\pm \mathrm{SD}$. One-way analysis of variance (ANOVA) followed by post hoc Tukey's test was performed by using GraphPadInStat 3.0 software. Values of $p<0.05$ were considered to be significant.

\section{Results}

\section{Effects of deprenyl on the activities of antioxidant enzymes} in the rat brain

In the present study we examined the activity of endogenous antioxidant enzymes using three experimental groups of animals: the first group was given saline (control animals), the second group was subjected to a low dose of deprenyl (LDD, $0.0025 \mathrm{mg} / \mathrm{kg}$ per day), and the third group to a high dose of deprenyl (HDD, $0.25 \mathrm{mg} / \mathrm{kg}$ per day) dissolved in saline for a period of 30 days. Treatment of rats with LDD significantly $(p<0.05)$ increased total SOD activity in the cortex $(0.74 \pm 0.03)$, striatum $(0.75 \pm 0.02)$, and CA1 region of the hippocampus $(0.75 \pm 0.02)$ compared to control $(0.53 \pm 0.02)$, while this activity was significantly $(p<0.05)$ reduced with HDD compared to the LDD group in the same regions of the brain. The activity of total SOD in the dentate gyrus of the hippocampus remained unchanged after both doses of deprenyl (Fig. 1A). The activity of CuZnSOD in the 
LDD group was significantly elevated only in the striatum region $(0.48 \pm 0.01)$ compared to control $(0.31 \pm 0.01)$, but reduced in the HDD group $(0.35 \pm 0.01)$ compared to the LDD group (Fig. 1B). A similar ratio between experimental and control groups was noted for MnSOD and total SOD activity. MnSOD activities in animals from the LDD group in the cortex $(0.31 \pm 0.02)$, striatum $(0.27 \pm 0.03)$, and CA1 $(0.29 \pm 0.03)$ were significantly increased compared to the control group $(0.15 \pm 0.02)$. Treatment with HDD significantly decreased MnSOD activity in the cortex $(0.15 \pm 0.02)$, striatum $0.014 \pm 0.02)$, and CA1 $(0.14 \pm 0.02)$ compared to the LDD group. MnSOD activity in the dentate gyrus was unchanged with LDD and HDD application (Fig. 1C). The activity of another important endogenous antioxidant
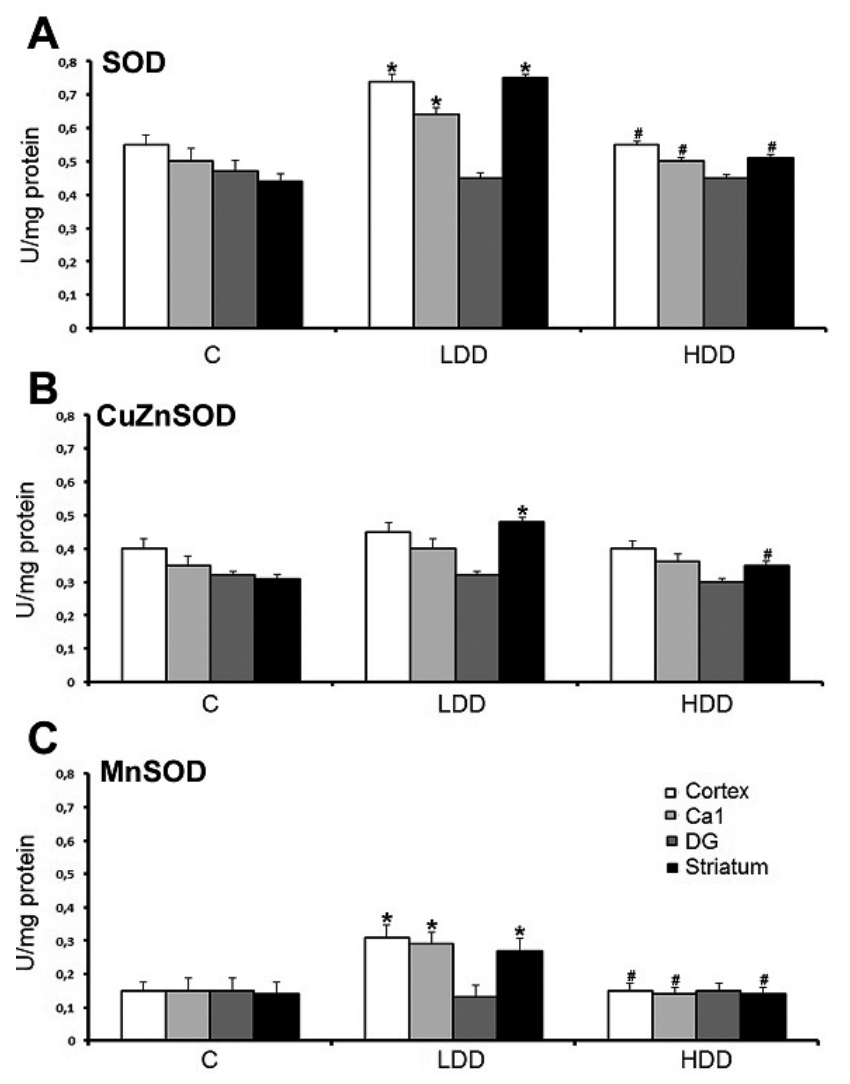

Figure 1. Enzymatic activity of total superoxide dismutase (SOD, A), copper-zinc superoxide dismutase (CuZnSOD, B) and manganese superoxide dismutase (MnSOD, C) measured spectrophotometrically (optical density $560 \mathrm{~nm}$ ) in different brain regions (cortex, hippocampal CA1, dentate gyrus and striatum) after the application of deprenyl for 30 days (i.p.) at a low dose (LDD, $0.0025 \mathrm{mg} / \mathrm{kg}$ per day, Sigma M003) or at a high dose (HDD, $0.25 \mathrm{mg} / \mathrm{kg}$ per day). Activity is expressed as international units per $\mathrm{mg}$ of protein $(\mathrm{U} / \mathrm{mg})$. Values were taken as the mean $\pm \mathrm{SD}$ of six animals in each group. Sampling was performed in triplicate. C, control animals; ${ }^{*} p<0.05$ compared to control, ${ }^{\#} p<0.05$ compared to the LDD group. enzyme, CAT, was significantly increased with LDD in the cortex $(27.34 \pm 3.11)$, striatum $(22.22 \pm 1.85)$, and hippocampal CA1 region $(16.62 \pm 2.15)$ compared to control $(10.33 \pm 1.01)$, while a smaller but still significant decrease was induced by HDD in the striatum $(9.85 \pm 1.09)$ compared to the LDD group $(22.22 \pm 1.85)$ and reached the level of the control group $(10.33 \pm 1.01)$ (Fig. 2). The activity of CAT remained unchanged in the dentate gyrus (DG) following the application of LDD and HDD.

\section{Effect of deprenyl on neurodegeneration in the hippocampal CA1 region}

Injured neurons were identified using Fluoro-Jade (FJ), a recently developed fluorescent marker of neuronal degeneration. FJ-positive cells were localised to the pyramidal cell layer of CA1 of the hippocampus. LDD and HDD caused a significant increase in FJ-positive neurons compared to control, but significant fewer FJ-positive cells were found with HDD compared to LDD (Fig. 3). To quantify the number of surviving neurons, we used immunohistochemistry for NeuN. A significant decrease in the number of NeuN positive cells was noted in the CA1 pyramidal cell layer of animals treated with LDD and HDD. There was also a significant difference between the LDD and HDD (Fig. 4).

\section{Discussion}

Deprenyl, an irreversible monoamine oxidase-B inhibitor, is used in the treatment of neurodegenerative disorders and has been reported to increase the lifespan of rats, possibly through antioxidant, neuroprotective, neurorestorative,

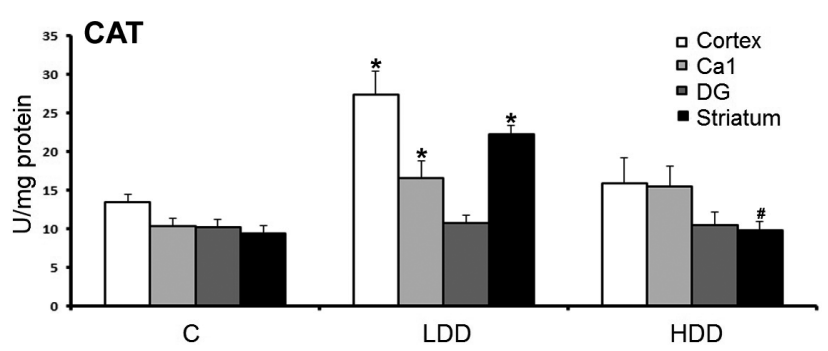

Figure 2. Enzymatic activity of catalase (CAT) measured spectrophotometrically (optical density $560 \mathrm{~nm}$ ) in different brain regions (cortex, hippocampal CA1, dentate gyrus and striatum) after the application of deprenyl for 30 days (i.p.) at a low dose (LDD, 0.0025 $\mathrm{mg} / \mathrm{kg}$ per day, Sigma M003) or at a high dose (HDD, $0.25 \mathrm{mg} /$ $\mathrm{kg}$ per day). Activity is expressed as international units per $\mathrm{mg}$ of protein $(\mathrm{U} / \mathrm{mg})$. Values were taken as the mean $\pm \mathrm{SD}$ of six animals in each group. Sampling was performed in triplicate. C, control animals; ${ }^{*} p<0.05$ compared to control, ${ }^{\#} p<0.05$ compared to the LDD group. 
neurotropic, and immunostimulatory properties (Magyar et al. 2010). It is known that deprenyl can upregulate activities of anti-oxidant enzymes such as SOD and CAT in brain dopaminergic regions (Kitani et al. 2002). In the present study we measured significant increase in the total SOD and CAT activity after application of the LDD. This was visible in all
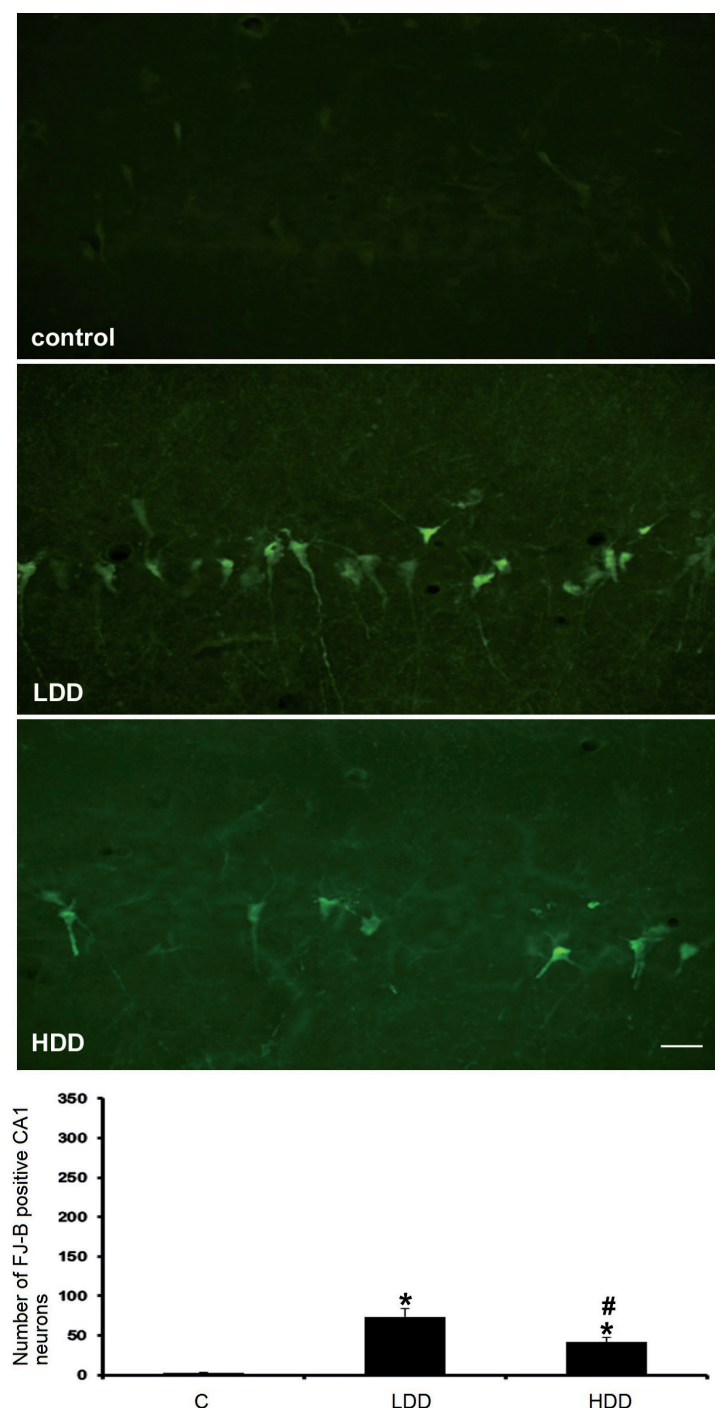

Figure 3. Representative microphotographs of neurodegeneration visualised by Fluoro Jade B staining in the hippocampal CA1 region. Quantification of fluorescence intensity counted in the middle of the linear part of the CA1 $(-3.3 \pm 0.2 \mathrm{~mm}$ posterior to the bregma) and expressed as the average of 10 measurements of positive hippocampal CA1 pyramidal neurons per $\mathrm{mm}$. Deprenyl was administered for 30 days (i.p.) at a low dose (LDD, $0.0025 \mathrm{mg}$ / $\mathrm{kg}$ per day) or at a high dose (HDD, $0.25 \mathrm{mg} / \mathrm{kg}$ per day). Values were taken as the mean \pm SD of six animals in each group. Scale bar $=50 \mu \mathrm{m} .{ }^{*} p<0.05$ compared to control, ${ }^{\#} p<0.05$ compared to the LDD group. observed areas: the cortex, striatum and CA1 region of the hippocampus. But in the DG the total SOD and CAT activity remained unchanged after the LDD administration. The activities of CuZnSOD and MnSOD were also significantly increased after the LDD administration. The increase in CuZnSOD activity was measured only in the striatum, but the increase of MnSOD activity was present also in cortex and CA1 area but not in the dentate gyrus. The results of the present investigation essentially indicate that administration of deprenyl significantly influences the related alterations in enzymatic antioxidants such as SOD and CAT. These data on the protective effect of deprenyl are probably related to its ability to strengthen the neuronal membrane, or a counteraction of free radicals and antioxidant property. Oxidative stress can cause damage to cell structure and function and chronic excessive inflammation. This can lead to damage or cell death. Protective mechanisms that exist to deactivate free radicals interfere with the cascade of events causing cell degeneration. By inhibiting oxidative stress, it may be possible to prevent the cell death. Deprenyl has been shown to protect against damage caused by a variety of agents and insults by a mechanism which may involve the scavenging of free radicals and/or the stimulation of antioxidant enzymes (Wu et al. 1993; Koutsilieri et al. 1994; Mytilineou et al. 1997a,b). SOD, CAT and GPx contribute to the elimination of reactive species and therefore to the reduction of the oxidative stress. We found that administration of deprenyl (LDD) resulted in an increase in both SOD and CAT enzyme activities in the rat brain. Interestingly, the high dose of deprenyl (HDD) did not cause an elevation of MnSOD activity compared to the 100-times lower dose of the same drug. In a group of animals with the applied treatment of the HDD the total SOD and CAT activity remained unchanged at the control values in the cortex, striatum, and hippocampus region.

The findings in female rats are in agreement with the earlier studies in which deprenyl was demonstrated to increase the antioxidant enzyme activities in the frontal cortex, striatum, heart, and spleen of male rodents (Bhattacharya et al. 2000; Kitani et al. 2002). However, deprenyl treatment of female rats significantly enhanced CAT and GPx activities in the hippocampus, in contrast to the results observed in deprenyltreated male rats, probably attributable to sex-associated differences, as described earlier. Since in last decades sex differences has been demonstrated in the pathophysiology of acute neurological injury, it should be mentioned and further investigated. Researches have already shown lesser susceptibility to postischemic and posttraumatic brain injury in females in experimental models. This is likely due to the effects of circulating estrogens and progestins, most importantly an antioxidant effect, reduction of A beta production and neurotoxicity, reduced excitotoxicity, increased expression of the antiapoptotic factor bcl-2, and activation of mitogenactivated protein kinase pathways (Roof and Hall 2000). 
Deprenyl can upregulate antioxidant enzyme activities in dopaminergic tissues other than in the brain, which is a reasonable explanation for the suggested causal relationship between the two effects of deprenyl, i.e. the upregulation of antioxidant enzyme activities and the survival of animals (Kitani et al. 1996, 1998). It has been clearly demonstrated that upregulation of SOD and CAT in selective brain regions produced by deprenyl effectively protects against neuronal

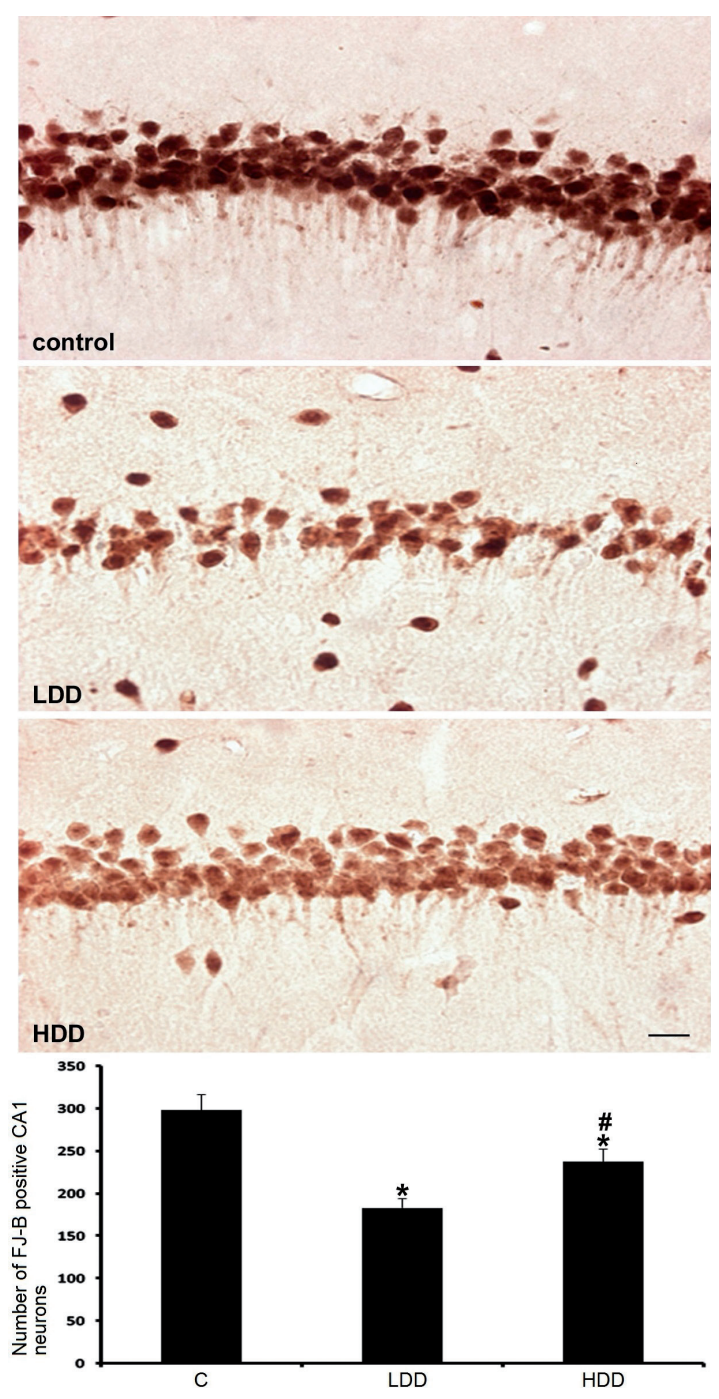

Figure 4. Representative microphotographs of NeuN immunohistochemistry of the CA1 region of the hippocampus. Quantification of the number of NeuN positive cells counted in the middle of the linear part of the CA1 $(-3.3 \pm 0.2 \mathrm{~mm}$ posterior to the bregma $)$ and expressed as the average of 10 measurements of positive hippocampal CA1 pyramidal neurons per mm. Deprenyl was administered for 30 days (i.p.) at a low dose (LDD, $0.0025 \mathrm{mg} / \mathrm{kg}$ per day) or at a high dose (HDD, $0.25 \mathrm{mg} / \mathrm{kg}$ per day). Values were taken as the mean \pm SD of six animals in each group. Scale bar $=50 \mu \mathrm{m} .{ }^{*} p<$ 0.05 compared to control, ${ }^{\#} p<0.05$ compared to the LDD group. death caused by an acute oxygen crisis due to a hypoxia-reperfusion paradigm in rats (Knollema et al. 1995). It has also been shown that deprenyl exerts neuro-protective effects, such as antiapoptotic (Maruyama et al. 1998; Maruyama and Naoi 1999; Kiray et al. 2008) and anti-Parkinson's (Tetrud and Langston 1989) effects.

Our results show that the endogenous antioxidants SOD and CAT, which have a considerable protective role in mammals, tend to increase in the brain after the administration of deprenyl. Since SOD generates hydrogen peroxide, which is biologically more toxic than other oxygen radicals, a concomitant increase in catalase activity is necessary to provide a beneficial effect from the increase in SOD activity. Deprenyl could contribute to neurological improvement by increasing the antioxidant capacity of brain tissue and by reducing the damage caused by oxidative stress reactions.

The difference in the results in the LDD and HDD can be explained be some dose-dependent factors. The dose of deprenyl for the induction of antioxidant enzymes is highly dependent upon the strain, age, sex and species of animal. Without glutathione peroxidase (or enough catalase) to eliminate hydrogen peroxide, SOD conversion of superoxide to hydrogen peroxide can lead to the formation of the deadly hydroxyl radical. The fact that both too much or too little deprenyl can reduce its anti-oxidant effect, and that optimum dose varies so greatly with strain, age, sex and species, makes the prediction of optimal dosages and the outcome very difficult.

LDD and HDD caused significant increases in degenerating neurons in the CA1 pyramidal cell layer, which corresponded to a significant decrease in the number of surviving NeuN positive cells in this hippocampal region.

Deprenyl upregulated the activities of antioxidant enzymes in different structures of the brain such as the cortex, striatum and hippocampus. LDD provides potent protection against oxidative stress by increasing SOD activity. Therefore, our results suggest that LDD could be useful for treatment of neurodegenerative diseases caused by oxidative damage. Even though deprenyl is commonly used in the treatment of neurodegenerative diseases, when it was delivered chronically to intact animals, we discovered its toxic effects, mainly demonstrated by the appearance of neurodegenerative changes in the CA1 region of the hippocampus. Paradoxically, higher numbers of Fluoro Jade positive neurons were seen in the LDD compared to the HDD group. Similar observation has been made in mice in non-neural model. Deprenyl did not exhibit any detectable protective effect to the thymocytes from apoptosis (Fang et al. 1995). The pharmacological mechanisms of deprenyl are somewhat complex. It is known that deprenyl combined with levodopa shows some degree of symptomatic improvement in early Parkinson's disease. But, there is no evidence that deprenyl decreased the excess mortality of Parkinson's disease. All in 
all, whether deprenyl has beneficiary effect on the cell death is not yet clear and requires additional studies.

Taken together, these results suggest that the LDD increases enzyme activities of CAT and SOD in the cortex, striatum and selectively vulnerable CA1 region of hippocampus but not relatively resistant dentate gyrus. However, the number of surviving neurons is higher in the HDD.

\section{Conclusions}

The previous research on positive effects of deprenyl administration in neurodegenerative disorders showed the antioxidant properties of deprenyl. Our results proved the effect of deprenyl treatment on the activity of endogenous enzymes in the selected areas of the rat brain. The most potential showed to be the administration of lower dosage of deprenyl which can be beneficial for reversing the oxidative damage in brain tissue. However, there are many aspects and questions that need to be properly studied to bring more insight in the possible neuroprotective outcomes by the use of deprenyl treatment. We also see the potential of further future research, especially in the brain ischemia models and the influence of deprenyl treatment on oxidative damage in ischemia-reperfusion processes.

Conflict of interest. The authors declare that there are no conflicts of interest.

Acknowledgement. This study was funded by the ERDF (ITMS 26220220043). The authors gratefully acknowledge the excellent technical assistance of Dana Jurusova.

\section{References}

Bhattacharya S. K., Bhattacharya A., Kumar A., Ghosal S. (2000): Antioxidant activity of Bacopamonniera in rat frontal cortex, striatum and hippocampus. Phytotherapy Res. 14, 174-179 https://doi.org/10.1002/(SICI)1099-1573(200005)14:3<174::AID-PTR624>3.0.CO;2-O

Bickford P. C., Adams C. E., Boyson S., Curella P., Gerhardt G. A., Heron C., Ivy G. O., Lin A. M., Murphy M. P., Poth K. et al. (1997): Long-term treatment of male F344 rats with deprenyl: assessment of effects on longevity, behavior, and brain function. Neurobiol. Aging 18, 309-318 https://doi.org/10.1016/S0197-4580(97)80313-2

Bradford M. M. A. (1976): Rapid and sensitive method for the quantitation of microgram quantities of protein utilizing the principle of protein-dye binding. Analytical Biochem. 72, 248-254 https://doi.org/10.1016/0003-2697(76)90527-3

Fang J., Zuo D. M., Yu P. H. (1995): Lack of protective effect of R()-deprenyl on programmed cell death of mouse thymocytes induced by dexamethasone. Life Sci. 57, 15-22 https://doi.org/10.1016/0024-3205(95)00238-2
Foley P., Gerlach M., Youdim M. B., Riederer P. (2000): MAO-B inhibitors: multiple roles in the therapy of neurodegenerative disorders? Parkinsonism Relat. Disord. 6, 25-47 https://doi.org/10.1016/S1353-8020(99)00043-7

Goth L. (1991): A simple method for determination of serum catalase activity and revision of reference range. Clin. Chim. Acta 196, 143-151 https://doi.org/10.1016/0009-8981(91)90067-M

Kiray M., Bagriyanik H. A., Pekcetin C., Ergur B. U., Uysal N., Ozyurt D., Buldan Z. (2006): Deprenyl and the relationship between its effects on spatial memory, oxidant stress and hippocampal neurons in aged male rats. Physiol. Res. 55, 205-212

Kiray M., Bagriyanik H. A., Pekcetin C., Ergur B. U., Uysal N. (2008): Protective effects of deprenyl in transient cerebral ischemia in rats. Chin. J. Physiol. 51, 275-281

Kitani K., Miyasaka K., Kanai S., Carrillo M. C., Ivy G. O. (1996): Upregulation of antioxidant enzyme activities by deprenyl. Implications for life span extension. Ann. New York Acad. Sci. 786, 391-409 https://doi.org/10.1111/j.1749-6632.1996.tb39079.x

Kitani K., Kanai S., Ivy G. O., Carrillo M. C. (1998): Assessing the effects of deprenyl on longevity and antioxidant defenses in different animal models. Ann. New York Acad. Sci. 854, 291-3061 https://doi.org/10.1111/j.1749-6632.1998.tb09910.x

Kitani K., Minami C., Isobe K., Maehara K., Kanai S., Ivy G. O., Carrillo M. C. (2002): Why (--)deprenyl prolongs survivals of experimental animals: increase of anti-oxidant enzymes in brain and other body tissues as well as mobilization of various humoral factors may lead to systemic anti-aging effects. Mech. Aging Dev. 123, 1087-1100

https://doi.org/10.1016/S0047-6374(01)00392-X

Knollema S., Aukema W., Hom H., Korf J., Horst G. J. (1995): Ldeprenyl reduces brain damage in rats exposed to transient hypoxia-ischemia. Stroke 26, 1883-1887 https://doi.org/10.1161/01.STR.26.10.1883

Koutsilieri E., O'callaghan J. F. X., Chen T. S., Riederer P., Rausch W. D. (1994): Selegiline enhances survival and neurite outgrowth of $\mathrm{MPP}(+)$-treated dopaminergic neurones. Europ. J. Pharmacol. 269, R3-4

https://doi.org/10.1016/0922-4106(94)90048-5

Magyar K., Szende B., Jenei V., Tabi T., Palfi M., Szoko E. (2010): R-deprenyl: pharmacological spectrum of its activity. Neurochem. Res. 35, 1922-1932 https://doi.org/10.1007/s11064-010-0238-8

Maruyama W., Takahashi T., Naoi M. (1998): (-)-Deprenyl protects human dopaminergic neuroblastoma SH-SY5Y cells from apoptosis induced by peroxynitrite and nitric oxide. J. Neurochem. 70, 2510-2515

https://doi.org/10.1046/j.1471-4159.1998.70062510.x

Maruyama W., Naoi M. (1999): Neuroprotection by (-)-deprenyl and related compounds. Mech. Aging Dev. 111, 189-200 https://doi.org/10.1016/S0047-6374(99)00066-4

Maruyama W., Yamamoto T., Kitani K., Carrillo M. C., Youdim M., Naoi M. (2000): Mechanism underlying anti-apoptotic activity of a (-)deprenyl-related propargylamine, rasagiline. Mech. Aging Dev. 116, 181-191 https://doi.org/10.1016/S0047-6374(00)00144-5 
McIntosh L. J., Hong K. E., Sapolsky R. M. (1998): Glucocorticoids may alter antioxidant enzyme capacity in the brain: baseline studies. Brain Res. 791, 209-214 https://doi.org/10.1016/S0006-8993(98)00115-2

Mytilineou C., Radcliffe P. M., Olanow C. W. (1997a): L- (7)-desmethylselegiline, a metabolite of selegiline [L-(7)- deprenyl], protects mesencephalic dopamine neurons from excitotoxicity in vitro. J. Neurochem. 68, 434-436 https://doi.org/10.1046/j.1471-4159.1997.68010434.x

Mytilineou C., Radcliffe P. M., Leonardi E. K., Werner P., Olanow C. W. (1997b): L-deprenyl protects mesencephalic dopamine neurons from glutamate-receptor-mediated toxicity in vitro. J. Neurochem. 68, 33-39 https://doi.org/10.1046/j.1471-4159.1997.68010033.x

Rego A. C., Oliveira C. R. (2003): Mitochondrial dysfunction and reactive oxygen species in excitotoxicity and apoptosis: implications for the pathogenesis of neurodegenerative diseases. Neurochem. Res. 28, 1563-1574 https://doi.org/10.1023/A:1025682611389

Roof R. L., Hall E. D. (2000): Gender differences in acute CNS trauma and stroke: neuroprotective effects of estrogen and progesterone. J. Neurotrauma 17, 367-388 https://doi.org/10.1089/neu.2000.17.367

Saravanan K. S., Sindhu K. M., Senthilkumar K. S., Mohanakumar K. P. (2006): L-deprenyl protects against rotenone-induced, oxidative stress-mediated dopaminergic neurodegeneration in rats. Neurochem. Int. 49, 28-40 https://doi.org/10.1016/j.neuint.2005.12.016

Schmued L. C., Hopkins K. J. (2000): Fluoro-Jade B: a high affinity fluorescent marker for the localization of neuronal degeneration. Brain Res. 874, 123-130 https://doi.org/10.1016/S0006-8993(00)02513-0

Singh R., Mishra M., Singh S., Sharma D. (2012): Effect of Ldeprenyl treatment on electrical activity, $\mathrm{Na}+, \mathrm{K}+$ ATPase, and protein kinase $\mathrm{C}$ activities in hippocampal subfields (CA1 and CA3) of aged rat brain. Indian J. Exp. Biol. 50, 101-109

Subramanian M. V., James T. J. (2010): Age-related protective effect of deprenyl on changes in the levels of diagnostic marker enzymes and antioxidant defense enzymes activities in cerebellar tissue in Wistar rats. Cell Stress Chaperones 15, 743-751 https://doi.org/10.1007/s12192-010-0177-y

Sun Y., Oberley L. W., Li Y. (1988): A simple method for clinical assay of superoxide dismutase. Clin. Chem. 34, 497-500

Tazik S., Johnson S., Lu D., Johnson C., Youdim M. B., Stockmeier C. A., Ou X. M. (2009): Comparative neuroprotective effects of rasagiline and aminoindan with selegiline on dexamethasoneinduced brain cell apoptosis. Neurotox. Res. 15, 284-290 https://doi.org/10.1007/s12640-009-9030-4

Tetrud J. W., Langston J. W. (1989): The effect of deprenyl (selegiline) on the natural history of Parkinson's disease. Science 245, 519-522 https://doi.org/10.1126/science. 2502843

Thomas T. (2000): Monoamine oxidase-B inhibitors in the treatment of Alzheimer's disease. Neurobiol. Aging 21, 343-348 https://doi.org/10.1016/S0197-4580(00)00100-7

Wu R. M., Chiueh C. C., Pert A., Murphy D. L. (1993): Apparent antioxidant effect of 1-deprenyl on hydroxyl radical formation and nigral injury elicited by MPP+ in vivo. Eur. J. Pharmacol. 243, 241-247 https://doi.org/10.1016/0014-2999(93)90181-G

Zhang Q., Li N., Zhou G., Lu X., Xu Z., Li Z. (2003): In vivo antioxidant activity of polysaccharide fraction from Porphyrahaitanesis (Rhodephyta) in aging mice. Pharmacol. Res. 48,151-155 https://doi.org/10.1016/S1043-6618(03)00103-8

Received: February 16, 2016

Final version accepted: June 2, 2016

First published online: November 30, 2016 